Andreja N. Inkret

\title{
Agnieszka, Antigona: Motiv Antigone v Katinu Andrzeja Wajde in Antigoni Dominika Smoleta
}

I.

Obstajajo prevodi, ki se bralcu zarežejo v spomin. Da je zame eden takšnih prevod Sofoklove Antigone Kajetana Gantarja, sem se znova zavedla pred kratkim, ob vnovičnem gledanju filma Katin Andrzeja Wajde. ${ }^{1}$ Vanj je poljski režiser namreč nedvoumno vpletel motiv Antigone. V nekaterih prizorih se zdijo aluzije na Sofoklovo tragedijo tako močne, da gledalcu budijo spomin na skorajda dobesedne replike in dogajanje $\mathrm{v}$ tej starogrški drami.

Pričujoči članek je spodbudil eden izmed prizorov v tem filmu; ta se zdi zanimiv predvsem zato, ker na domiseln način zgoščeno in večplastno podaja vsebinske poudarke, ki se zdijo za Antigonino dejanje ključni. Tako Wajda na neki način iznajde nadomestek za specifično dramaturško tehniko, ki so jo atiški dramatiki radi uporabljali v svojih igrah, $s$ pridom pa se je poslužuje tudi Sofokles v enem izmed najbolj pretresljivih prizorov Antigone. $\mathrm{V}$ mislih imam elemente, prevzete iz ritualov (molitev, porok, priprošenj, pogrebov itd.), ki so jih antičnih gledalci dobro poznali iz vsakdanjega življenja in jih - transponirane $\mathrm{v}$ dramsko besedilo in na oder - dojemali predvsem na čustveni, iracionalni ravni. Ker so takšni rituali s svojimi specifikami v veliki meri zavezani konkretnemu času in prostoru, $\mathrm{v}$ katerih so grške drame nastajale, so tudi njihovi učinki na sodobnih odrih le težko poustvarjeni, sodobne obdelave antičnih mitov pa jih redko posredujejo na enako zgoščen način.

1 Katyn, Poljska 2007, režija Andrzej Wajda, scenarij (po romanu Andrzeja Mularczyka Post Mortem) Andrzej Wajda, Wladyslaw Pasikowski in Przemyslaw Nowakowski. 
Razmislek o prizoru iz filma, v katerem poljskemu režiserju uspe na enem mestu z vso metaforično polnostjo ponazoriti simboliko katinske Antigone, nam bo služil kot odskočna deska za vprašanje, kakšno funkcijo ima mit v tem filmu, z drugimi besedami - zakaj se v njem pojavi. Ob tem je film Katin zanimiv še iz enega razloga; primerljiv je namreč z najslavnejšo slovensko različico iste mitološke zgodbe - Antigono Dominika Smoleta. ${ }^{2}$ Čeprav gre v osnovi za različni umetniški deli, ${ }^{3}$ ju druži povezovanje mita o Antigoni s travmatičnimi dogodki, vezanimi na drugo svetovno vojno. Wajda ga vplete v zgodovinski film, posvečen tragičnim medvojnim dogodkom v Katinskem gozdu in dogajanju v zvezi z njimi. Leta 1940 je sovjetska oblast načrtno pobila več tisoč poljskih oficirjev in intelektualcev, njihova smrt pa je še dolga desetletja ostala tabuizirana, saj Sovjeti pomora niso priznali, temveč so trdili, da so ga leto kasneje zagrešili Nemci. Razumevanje Smoletove Antigone so prav tako ključno zaznamovali dolgo zamolčani zgodovinski dogodki, vezani na drugo svetovno vojno. Vprašanje, če je Dominik Smole v času nastanka slovenske Antigone vedel za slovenske povojne poboje in jih želel tematizirati, ostaja odprto. A ne glede na to je neizpodbitno dejstvo, da je takšno videnje te drame interpretacija, ki ostaja vezana na to delo. ${ }^{4}$ Kratka synkrisis Wajdove in Smoletove Antigone, ki sledi v drugem delu tega prispevka, bo dodatno osvetlila vprašanje o vlogi mita v dveh delih, ki sta vezani na primerljivo zgodovinsko tematiko, a sta nastali v dveh različnih obdobjih. Obenem bo spodbudila vprašanje, v kolikšni meri - če sploh - je Sofokles tudi na slovensko različico vplival s svojimi dramskimi tehnikami, ne le kot poglavitna antična idejna referenca za mit o Antigoni.

Nenazadnje bo interpretacija dveh sodobnih del, ki črpata iz antike, tudi kot upam - hommage profesorju, ki je tako v spremnih besedilih k prevodom in kot v predavanjih študentom rad poudarjal, kako velik pomen imajo sodobne obdelave antičnih tem in motivov.

2 Drama je nastala leta 1959, prvič je bila objavljena v letih 1960/1961 (v reviji Perspektive) in prvič uprizorjena leta 1960 (Oder 57, režija Franci Križaj): glej Smole, Zbrano delo, 173, 187, 197.

3 Začenši seveda s pomembnim dejstvom, da je eno film, drugo dramsko besedilo. Ker nas bo zanimala predvsem primerjava del na idejni, interpretativni ravni, našemu razmišljanju kot upam - ne bo v preveliko škodo, če načelne razlike in podobnosti teh dveh različnih umetniških medijev ne bodo predmet tega zapisa. O filmskih upodobitvah antične tragedije sicer glej Michelakis, "Greek Tragedy in Cinema", passim.

4 Glej Smole, Zbrano delo, 269 in sl. Primerjaj tudi prvo številko Delove priloge Pogledi (letnik 1, št. 1, 7. april 2010), ki je bila posvečena prav Smoletovi Antigoni; ta je prav letos praznovala petdesetletnico svoje prve gledališke uprizoritve. Po naključju je bil tudi film Katin letos še posebej aktualen, saj mineva sedemdeset let od dogodkov v Katinskem gozdu (obletnica se bo žal zapisala $\mathrm{v}$ spomin tudi zaradi tragične letalske nesreče, $\mathrm{v}$ kateri je življenje izgubil del poljskega političnega vrha, ki je potoval na spravno slovesnost). 
Grška drama je zvezana $\mathrm{z}$ ritualom. ${ }^{5}$ Po Aristotelu izvira iz ritualne zborske himne, ditiramba. Če nič drugega, na njeno povezavo z ritualom skozi zlato dobo atiškega gledališča kaže zbor, ki - kot v osnovi in po izvoru ritualni element - dejavno sodeluje v zgodbah, kot jih v gledališču oblikujejo dramatiki. ${ }^{6}$ A ritualni element je vpisan tudi v samo naravo grškega gledališča, saj je to obstajalo ne le kot umetniško tekmovanje in dovršena institucija pod pokroviteljstvom atenske polis, temveč tudi kot pomemben religiozni praznik. $\mathrm{Na}$ drugi strani so interpreti mnogokrat prepoznali povezanost rituala in posamičnih dram. ${ }^{7}$ A grški tragiški in komični dramatiki 5. in zgodnjega 4. stoletja pr. n. št. tudi večkrat upodabljajo rituale na odru. To dejstvo je seveda zanimivo samo po sebi; trdili bi lahko, da drama - s tem, ko uprizarja na odru sebi sorodne ritualne institucije - v nekem zelo elementarnem smislu podvaja svojo naravo, lahko bi rekli, da samo sebe postavlja na ogled. ${ }^{8}$ A takšno (morebitno) metateatrsko samopredstavljanje ni nikoli namenjeno samo sebi; odrske upodobitve ritualov se zdijo vedno utemeljene na vsebinski ravni.

Načini, kako dramatiki vključujejo rituale v grško dramo in nato na gledališko prizorišče, so raznovrstni. Rituali so lahko zgolj opisani kot izvenodrsko dogajanje (takšna sta na primer opisa Ajgistovega žrtvenega praznovanja v Evripidovi Elektri, 783-839, ali pa Ksutovo žrtvovanje v Evripidovem Ionu, 1123-1205) ali prikazani na odru, kot del dogajanja. V grških igrah tako zasledimo ritualne procesije (npr. v Aristofanovih Aharnjanih, 241-79),

5 Vprašanje, kako definirati ritual, je seveda kompleksno in presega temo in obseg tega članka. Za naše potrebe lahko navedemo razlago, kot jo podaja Tambiah, Culture, Thought, and Social Action, 128: »Ritual is a culturally constructed system of symbolic communication. It is constituted of patterned and ordered sequences of words and acts, often expressed in multiple media, whose content and arrangement are characterized in varying degree by formality (conventionality), stereotypy (rigidity), condensation (fusion), and redundancy (repetition). « Prim. tudi Martin, »Ancient theatre and performance culture«, 36-39, Graf, "Religion and drama«, passim.

6 Prim. Golder, »Preface«, passim.

7 Glej na primer Foley, Ritual Irony, passim; Bowie, Aristophanes, passim; Tzanetou, »Almost Dying, Dying Twice«, passim.

8 Ob tem je pomembno - kot poudarjajo mnogi preučevalci antike - da je bila atenska družba 5. in 4. stoletja pr. n. št. zaznamovana z raznovrstnimi institucionaliziranimi, pa tudi privatnimi prireditvami izrazito teatralnega značaja (anglosaksonski interpreti atensko kulturo radi opisujejo s terminom performance culture). Rehm, Greek Tragic Theatre, 3, tako poudarja: »Athenian society as a whole was imbued with a sense of event, of things said and done in the context of conventional frame, so that participation entailed both a commitment to the moment and a critical distance from it. Today, for example, we perceive a great difference between participating in a ritual where issues of belief are paramount, and attending a theatrical performance where suspension of disbelief is at issue. Ancient Athenians seem to have viewed these events as a continuum of performance rather than as opposed attitudes to the world.« Prim. tudi Goldhill, »Programme notes«, 20-26. 
pogrebne slovesnosti (v Sofoklovem Ajantu, 1402-20, Evripidovih Priprošnjicah, 778-1234), molitve in darovanja bogovom (npr. v Ajshilovih Peržanih, 598-680, Evripidovi Heleni, 1094-1104, Aristofanovih Ptičih, 848-1118, Praznovalkah tezmoforij 39-57), formalne priprošnje (npr. v Evripidovem Ionu, 1250-1319), ritualizirane prisege (v Evripidovi Medeji, 745-55), obredna očiščenja (npr. v Evripidovi Ifigeniji pri Tavrijcih, 1221-33). Poslužujejo se jih tako tragiški kot komični pesniki; če tragiki - poenostavljeno rečeno - stremijo za neke vrste avtentičnostjo (tudi če jih ustvarijo na novo), jih komiki seveda $\mathrm{z}$ velikim veseljem in domišljijo parodirajo. ${ }^{9}$

A dramatiki še večkrat v svoje drame vpletajo zgolj ritualne elemente, ne celotnih ritualov. V tem smislu je tak že zbor, ki - kot piše P. E. Easterling - »ni nikoli le skupina sočutnih očividcev ali prič ... pač pa vedno tudi choros, pripravljen na izvajanje speva po vzoru ritualne pesmi in plesa ob spremljavi primerne glasbe «. ${ }^{10}$ Pajani in druge obredne pesmi, ki jih pojejo zbori, niso kontekstualizirani kot ritualno dogajanje, temveč nanj - s posamičnimi elementi, značilnimi za rituale, ki jih občinstvo prepozna ali zgolj občuti kot takšne - le namigujejo in tako bogatijo dogajanje. Še bolj zanimivi se zdijo ritualni elementi takrat, ko niso del konvencije, pač pa so ustvarjeni zato, da $\mathrm{v}$ gledalcu zbudijo določene učinke in občutja. $\mathrm{V}$ takšni uporabi ritualnih elementov se zdi posebej subtilna tragedija; ne gre ji namreč za razumsko razpoznavne učinke, temveč za občutja, ki se največkrat dogodijo na čustveni, nerazumski ravni. Eden izmed najboljših tovrstnih primerov se zdi prav prizor iz Sofoklove Antigone, ki mu bomo vzporednico poiskali v Wajdovem filmu.

Naslovno junakinjo med pesmijo, ki si jo izmenjujeta Antigona in zbor tebanskih starcev (801-943), stražarji vodijo iz palače proti kamniti votlini, kamor jo je ukazal zapreti Kreon. Čeprav Antigona še živa stopa proti »kra-

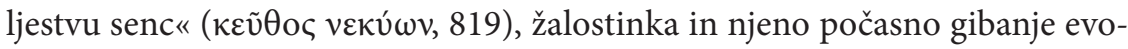
cira ritual pogreba, pogrebno procesijo (ekphora), v kateri v resničnem življenju pokojnika žalujoči spremljajo na poslednjo pot. ${ }^{11}$

9 Dober primer so Aristofanove Praznovalke tezmoforij s komično verzijo antičnih tezmoforij, ritualnega praznovanja, ki so se ga lahko udeleževale le ženske. Aristofan obredno praznovanje prilagodi po svoje - njegova odrska predstavitev tezmoforij je pravzaprav parodija (zgolj moških) atenskih političnih zborovanj v ekleziji. Na to opozori Aristofanov Evripid že na samem začetku drame (82-84), ko reče, da bodo ženske na tezmoforijah zborovale

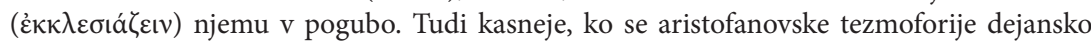
odvijajo na odru, smo priče kombinaciji obeh modelov. $\mathrm{V}$ tem smislu je zanimiva predvsem uvodna molitev (295-311), v kateri komediograf kontrastno meša ritualno besedišče s političnimi termini, ki so se uporabljali na zborovanjih v ekleziji. Prim. Haldane, »A scene in the Thesmophoriazusae (295-371)«, 40.

10 »Tragedy and Ritual«, 8. Prevod A. I.

11 Kot poudarja A. Brown, ad loc., je njena smrt predvidena kot strašna »smrt za živa«: »In realistic terms, what Antigone must expect to endure is a period of imprisonment ending, sooner or later, with her death by suicide or starvation. But these are not the terms in which her fate is envisaged. Instead she and the Chorus present, if anything, a still more horrifying prospect: that of a living death, to begin at the moment of her 'entombment' and to last for ever. This reflects the function of Greek funerary ritual.» 
A to ni edini tovrstni namig v tem prizoru. Antigonina smrt je vzporejana s še enim pomembnim ritualom: poroko. Na to najprej opozori Kreon, ki sinu Hajmonu svetuje (653-54): ${ }^{12}$

To dékle kot sovražnico izpljuni,

naj v Had odide, tam si išče snubca!

Metafora se do določene mere konkretizira $\mathrm{v}$ omenjenem prizoru. Zbor poje o tem že ob Antigoninem vstopu na prizorišče (801-805):

Ob tem pogledu ne morem več,

ne morem zadržati solz:

Antigona gre, odhaja od nas

v Hadove svatbene dvore,

kjer nas čaka spanje nevzdramno.

Tudi Antigona to, kar se ji dogaja, opisuje z isto metaforo (806-17):

Glejte me, rojaki moji!

Zdaj grem na poslednjo pot,

zadnjikrat še vidim

sončno luč! In níkdar več!

Had, ki vse v temò zagrinja,

vodi živo me od tod

$\mathrm{k}$ hladim vodam Aheronta.

Niso še prižgali svatovske mi bakle,

niso še zapeli svatovske mi pesmi.

Smrt me bo objela

$\mathrm{v}$ noč poročno.

Antigona in zbor torej dogajanje - Antigonino stopanje naproti kazni, ki pomeni smrt - povežeta s poroko in pogrebom. Tako gledalce na subtilen način opozorita, da odrska akcija vsebuje elemente, ki jih je moč razumeti kot ritualne: pesem, ki si ju izmenjujeta, je žalostinka; Antigonino počasno gibanje, spremljano s pesmijo, deluje kot procesija. Oboje, petje žalostink in stopanje $\mathrm{v}$ procesiji so del pogrebne ekphore kot tudi poročnih slovesnosti, ko svatje spremljajo nevesto v ženinovo bivališče. ${ }^{13}$ Ko zbor Antigonino odrsko akcijo definira kot hojo proti »Hadovim svatbenim dvorom « (804), budi asociacije na elemente, ki so skupni obema ritualoma. Prizor seveda ne prikazuje ne poroke in ne pogreba, a z odrskimi sredstvi, ki se napajajo ob vsakodnevnih

12 Vse navedke iz Sofoklove Antigone navajam v prevodu Kajetana Gantarja.

$13 \mathrm{O}$ pogrebnih procesijah govori Brown, ad loc.; o namigih na ritual poroke $\mathrm{v}$ tem in drugih prizorih Kavoulaki, ПОМПАI, 265 in sl. 
ritualih in učinkujejo na gledalca predvsem na čustveni ravni, bogati akcijo v metaforičnem smislu.

Z uporabo elementov, ki so skupni dvema ritualoma, prevzetima iz resničnega življenja, Sofokles ustvari prizor, ki budi mnoge konotacije in ustvarja prostor za različne interpretacije. Dramatik s takšnimi odrskimi sredstvi efektivno (vsekakor z več učinka, kot bi ga imele samo besede) na specifično gledališki način ustvarja vsebinske poudarke, ki so za dramo bistveni. Najprej velja omeniti samo dejstvo, da se je Antigona ob Kreontovi prepovedi in smrti bratov zavezala svetu mrtvih. To je na subtilen način poudarjeno $\mathrm{v}$ tem prizoru, saj Antigona živa in pri polni zavesti stopa svoji smrti naproti; še več, namig na pogrebni ritual lahko razumemo v smislu, da metaforično stopa za lastnim pogrebom. Če je njena odpoved življenju na začetku zvezana s trdno odločenostjo, v katero Antigona ne dvomi - to se izkristalizira predvsem v dialogih z Ismeno, ki za sodelovanje pri pokopu Polinejka nima poguma, in s Kreontom -, se v tem prizoru vendarle kaže tudi njena žalost nad izgubo življenja. Groza nad bližajočo se smrtjo pride zgoščeno do izraza skozi asociacije na poročni ritual, ki - ker se spričo bližajoče se smrti ne bo zgodil nikoli podčrtuje zarezo z življenjem na tem svetu.

Ta vsebinsko pretresljiv in dramaturško domišljen prizor torej slika hkrati žalostinko za poročnih ritualom, kot tudi lamentacijo nad lastnim presekom z življenjem, nad metaforično smrtjo, ki ji je Antigona podvržena še za časa življenja. Na poseben način tudi poudarja pretresljivo dejstvo, da se junakinja znajde v nekakšnem vmesnem prostoru, nekje med življenjem in smrtjo (851-53):

Joj, jaz nesrečnica, ki nimam doma

med živimi in ne med mrtvimi,

ne med ljudmi in ne med sencami!

III.

Primerljiv prizor vsebuje Wajdov Katin. Zgodba o Antigoni je v filmu sicer sodobna zgodba, postavljena $\mathrm{v}$ čas štiridesetih let preteklega stoletja. Je ena izmed zgodb, spletenih okoli množičnega poboja poljskih oficirjev in inteligence, sovjetskega zločina iz leta 1940, za katerega je dolgo veljala uradna razlaga, da se je dogodil leto kasneje, ko je bil teritorij pod nemško oblastjo. Katinska Antigona je torej junakinja nekega drugega časa; ima sodobno ime, živi na Poljskem, v mestu Krakov. S Sofoklovo Antigono si deli v prvi vrsti značilno, prepoznavno situacijo: njeno življenje usodno zaznamuje smrt brata, ki je bil umorjen v Katinskem gozdu, in sicer do mere, da ogrozi lastno življenje - v tem se razlikuje od svoje sestre, katere prepričanje in ravnanje je manj junaško. Imena treh junakov, ki delujejo kot različice antičnih, se pomenljivo začenjajo na isto črko kot tista starogrških protagonistov: Agnieszka 
je Antigona, Irena je Ismena, Piotr je Polinejkes. Pravica do pokopa, ki jo zagovarja Sofoklova Antigona, je v Katinu seveda prilagojena zgodovinski situaciji; Agnieszka se odloči mrtvemu bratu postaviti simbolno spominsko ploščo, ki vsebuje dejansko letnico njegove smrti. Dejanje je za oblast sporno zato, ker so z njim posredno izpostavljeni resnični storilci dejanja.

Tudi Agnieszkin upor na simbolni ravni pomeni zavezo svetu mrtvih. Besede Sofoklove Antigone, »Moja duša / že zdavnaj mrtva je, le mrtvim služi!« (560-61), dobijo skoraj dobeseden odmev v poljskem filmu. Agniezska namreč $\mathrm{v}$ pogovoru s sestro pravi, da je - za razliko od slednje, ki je našla svoj prostor v tem novem svetu, - sama vsa v tistem, kjer je Piotr. Pri tem, kot poudari, ne gre toliko za odločitev med svetom živih in svetom mrtvih, temveč med svetom morilcev in umorjenih. Verjetno ni naključje, pač pa dobro premišljena poteza, da se Agnieszkina simbolna zaveza svetu umorjenih dogodi ravno v gledališču, kjer - tu je referenca na antično tragedijo tudi najbolj očitna - pripravljajo uprizoritev Antigone. Prav dogajanje v gledališču bi lahko po izrazni moči primerjali z opisanim prizorom iz Sofoklove tragedije; je globoko simbolno, večpomensko, deluje na čustvenem nivoju, obenem pa na zgoščen način podaja ključne vsebinske poudarke, kot smo jih izpostavili že v zgoraj opisanem prizoru iz Sofoklove Antigone.

Agniezska se v gledališče odpravi prodat svoje čudovite, dolge svetle lase. Kot izvemo, so Nemci iz teatra pobrali vse lasulje in gledališki mojstri odkupujejo lase, iz katerih izdelujejo nove; Agnieszka z izkupičkom nabavi in da vklesati napis na nagrobnik mrtvega brata. Prav lasje tako dobijo pri Agnieszkinem simbolnem aktu, dokončni zarezi s svetom živih (nagrobni napis $\mathrm{z}$ dejansko letnico bratove smrti v Katinskem gozdu seveda neposredno ogroža Agniezskino življenje) poseben, simbolen pomen. Gledalci smo nanje opozorjeni že prej; igralka je v enem izmed prejšnjih prizorov posneta v hrbet, na katerem ji poskakuje čudovita, svetla kita. Ko stopa proti gledališču, tik preden se prepusti škarjam gledališkega lasuljarja, so njeni lasje razpuščeni in v vsem svojem razkošju plapolajo v vetru. V Agnieszkini odpovedi lasem je vsekakor nekaj arhetipskega; ostriženi lasje so v mnogih kulturah ritualni znak žalovanja ob smrti ljubljenih. ${ }^{14}$ Agnieszka sicer izvrši to dejanje - strogo gledano zaradi potrebe po denarju, a dejstvo, da se ostriže zaradi mrtvega brata, da svoje lase takorekoč nameni mrtvemu, je vendarle pomenljivo. Za nameček lasuljar, tik preden se loti striženja, reče, da se je škoda odpovedati tako lepim lasem; Agnieszko vpraša, če njen mož ve za to. Slednja mu s stisnjenimi zobmi reče le, naj opravi svoje delo. Agnieszkin odgovor kaže, da ji je opazka očitno neprijetna; opomni nas, da njena zaveza svetu mrtvih oziroma umorjenih pomeni obenem zarezo s svetom živih, z življenjem torej, kamor sodi (ali je

14 Glej Bendann, Death Customs, 89-95. Veliko tovrstnih primerov vsebujejo tudi grška dramska besedila. Prim. npr. Evripidovo Heleno, kjer naslovna junakinja pravi (367-69; prevod Jelena Isak Kres): »Matere so izgubile otroke, / dekleta, sestre ubitih bratov / so darovale svoje ostrižene lase / ob valovih frigijske reke Skamandra." 
sodila $)^{15}$ poroka, mož, moški, ali vsaj nekdo, ki mu morajo biti junakinjini svetli, dolgi lasje še posebej ljubi. Tudi v tem filmskem prizoru torej lahko najdemo namig na poroko in pogreb, dva pomembna rituala, ki ju povezuje Agnieszkina večpomenska odpoved lasem.

A striženje $v$ gledališču ima še en podton: tega $z$ veliko metaforično močjo pooseblja igralka, ki bo v gledališki predstavi Antigone igrala naslovno vlogo. Najprej jo ugledamo sede na odru, samo pred praznim avditorijem, s pogledom, zamaknjenim nekam v daljavo; najbolj bije v oči dejstvo - tudi zato, ker jo ugledamo takoj potem, ko Agnieszka s svojimi bogatimi lasmi vstopa $\mathrm{v}$ gledališče -, da je povsem brez las. Pojavi se tudi v prostoru, kjer lasuljar striže Agniezskine lase. Pove, da je preživela taboriščno izkušnjo v Auschwitzu, po kateri ji lasje ne bodo več zrastli. Zdaj se že veseli lasulje iz Agniezskinih las in recitira v vlogi Antigone (464-71):

Kdor kakor jaz živi v tegobah samih, temu prinese smrt le čist dobiček.

Če mi odmerišs smrt, me ne boli.

Bolelo bi me le, če bi pustila, da truplo bratovo nepokopano trohni. Nič drugega me ne boli. Če se ti zdi norost, kar jaz počenjam, je, kot bi norec mi norost očital.

Povezavo med situacijama, v katerih sta se znašli Sofoklova Antigona na eni strani in Wajdova Agnieszka na drugi, podkrepi lasuljarjeva omemba stare vraže, da človek skupaj z lasmi nekoga drugega prevzame tudi njegovo usodo; Agnieszkin komentar, da tega ne bi privoščila niti največjemu sovražniku, se zdi do neke mere ironičen. Človek se namreč vpraša, če ne velja tudi obratno: za gledališko igralko, ki bo odigrala Antigono, se zdi, kot bi prihajala iz »kraljestva senc« nazaj v življenje. Če je spomin na poprejšnje življenje, prepredeno s travmatično taboriščno izkušnjo, brazgotinasta gola glava, ji bodo Agnieszkini lasje - pa čeprav le za čas predstave - omogočili dokončno simbolično vrnitev nazaj. Agnieszka, nasprotno, z aktom striženja, polnim podtonov, dokončno potrdi svoj odhod med sence. Agnieszka torej z lasmi ne "podarja « igralki le svoje usode, pač pa življenje, a zato hkrati morda - po nekakšni recipročni logiki, ki sledi iz starega reka - tudi sama prevzema nase usodo, ki je po svojem bistvu podobna tej, ki jo je igralka preživela in jo metaforično zaznamujejo za vedno izgubljeni lasje.

Lahko bi torej rekli, da se tudi Wajdova Agnieszka - po vzoru Sofoklove Antigone - v prizoru v gledališču znajde v vmesnem prostoru med »živimi

15 Lasuljar in igralka, ki je prisotna, Agnieszkino zadrego ob vprašanju o možu razumeta kot zaskrbljenost ob tem, da se mož še ni vrnil domov (verjetno iz ujetništva). Agnieszka tega niti ne zanika niti ne potrdi. 
in ... mrtvimi«, med »ljudmi in ... sencami«. Ta kmalu dobi bolj konkretno obliko, sodobno inačico tiste, o kateri govori Sofokles. Potem ko na grob postavi spomenik, Agnieszko odpeljejo na zaslišanje na neznan kraj. Poljska Antigona se seveda ob vprašanjih zasliševalcev ne zlomi in ne pristane na njihove zahteve (podpisala naj bi dokument, da so katinski pomor storili Nemci). Poslednjikrat jo vidimo, kako se po mrzlih, kamnitih stopnicah spušča $\mathrm{v}$ temačno klet. Ta skrivni zapor pod zemljo nas spomni na kazen, ki se je pri Sofoklu domisli Kreon (774-75):

Tam, kamor ne zaide sled človeška, jo živo bom zazidal v skalnat grob.

IV.

Dogajanje v gledališču je najbolj eksplicitno glede antične reference, vpete $\mathrm{v}$ zgodovinsko filmsko pripoved, spleteno okrog dogodkov v Katinskem gozdu. Ta je nazadnje tudi povsem dobesedna: če se prej ime mitološke junakinje ne omeni neposredno, ga ob Agnieszkinem odhodu iz teatra ugledamo na gledališkem plakatu, ki napoveduje uprizoritev Antigone. Prizor v gledališču je tudi prvi od treh prizorov v Katinu, ki se zdijo neposredno navdahnjeni ob dramaturški kompoziciji ključne antične reference za antigoninski mit, Sofoklovi Antigoni.

Drugi je dialog med Ireno in Agniezsko, ki sledeč Sofoklovi genialni domislici vzpostavi razlike $\mathrm{v}$ značajih in življenjskih nazorih dveh sester, kot se izkristalizirajo ob smrti njunega brata. Tudi v Katinu torej sestri zavzameta različni stališči do resnice o Piotrovi smrti, ki temeljita $\mathrm{v}$ njunem odnosu do povojne stvarnosti. Agnieszka, kot že zapisano, poudari, da se je - za razliko od Irene - sama zapisala svetu umorjenih, ne morilcev. A ta izjava se zdi ob Ireni, kot je predstavljena v filmu, vendarle pretirana. Wajda svoje Ismene - do neke mere podobno kot Sofokles - ne izriše povsem negativno. Če antična Ismena sicer nima poguma za dejanje, a bi - ko je to enkrat storjeno - umrla skupaj z Antigono (prim. 537-49), ${ }^{16}$ se Irenina pozitivna stran kaže na drugačen način. Kot Sofoklova Ismena sicer meni, da je upor zoper oblast brez smisla, ${ }^{17}$ saj Poljska ne bo nikoli več zares svobodna, a vendar močno verjame, da je dolžna znotraj takšne podjarmljene dežele zgraditi neke vrste svobodni svet. V tej smeri tudi aktivno deluje. Kot ravnateljica gimnazije je v prepričanju, da Poljska potrebuje mlade, izobražene ljudi, pripravljena na tihem tvegati. Seveda ponovno ni naključje, da se to pokaže ravno v prigodi z mladeničem, ki si želi po vojni pridobiti izobrazbo, da bi se lahko vpisal na univerzo, in ob vpisu v gimnazijo kot kraj in letnico smrti svojega

16 To dejstvo se zdi v mnogih interpretacijah Ismene spregledano.

17 Prim. Ismenine besede pri Sofoklu (68-69): »Upirati / premôči se, bi ne imelo smisla.» 
očeta vpiše »Katin, 1940«. Irena ga najprej posvari, a ko mladenič jezno odvihra, iz pogovora $\mathrm{z}$ enim izmed učiteljev izvemo, da mu bo kljub temu omogočila šolanje in ga po svojih najboljših močeh zaščitila. Mladeniča lahko razumemo kot nekakšno inačico Agnieszke; dejstvo, da je Irena zanj pripravljena tvegati lastni položaj, je vsekakor pomenljivo. ${ }^{18}$ Irena si prizadeva za izobrazbo in vzgojo nove poljske inteligence, takšne, ki bo - če si dovolimo pogledati naprej v prihodnost - ne nazadnje sposobna tudi vzpostaviti odnos do medvojnih travm in preseči tabuje, vključno $\mathrm{z}$ resnico o dogodkih v Katinskem gozdu. Če je Ismena sicer v modernih upodobitvah večkrat predstavljena kot antipol poduhovljeni Antigoni - kot senzualna, čutna ženska, ${ }^{19}$ to ne velja za Wajdov film: Irena se zdi tako po razmišljanju kot videzu asketska, morda celo bolj od Agnieszke. ${ }^{20}$

Poleg dialoga med Ireno in Agnieszko ter prizora v gledališču, ko Agnieszka žrtvuje svoje lase, močno spominja na Sofoklovo dramo tudi omenjeni prizor v skrivnem bunkerju, kjer junakinjo zaslišujejo. Kot že opisano, bunker vsebuje zapor, ki budi asociacije na Sofoklov »skalnat grob«.

Namen teh treh prizorov se zdi jasen: mit daje zgodovinskim dogodkom, kot jih kaže film Katin, nadčasovno in univerzalno dimenzijo. ${ }^{21}$ Agnieszkino, pa tudi Irenino ravnanje ob bratovem umoru se sicer izriše kot eden izmed odnosov, lahko bi rekli celo principov, ki jih različne ženske, matere, sestre, žene, hčerke kažejo do smrti svojih ljubljenih. Katin je namreč v prvi vrsti film o ženskah, o tistih, ki čakajo novic o svojih dragih in se morajo spoprijeti s strašnimi sporočili o njihovi smrti ali pa - kar je lahko še huje - z molkom o njihovi usodi. A Agnieszka in $\mathrm{z}$ njo Irena sta hkrati tudi več kot le sestri, ki sta v katinskem pomoru izgubili brata: presegata zgodovinsko "podrobnost«, da gre za Katin in leto 1940, ter opozarjata na univerzalnost žalosti ob izgubi bližnjih in težkih odločitev, ki jih mora človek sprejeti, če je njihova smrt prepredena $\mathrm{z}$ lažmi in zamolčanji. Navezava na Sofoklovo Antigono kot ključno besedilo za mit o Antigoni je ob tem razumljiva: asociacija na Antigono je implicitna in mora biti zato razpoznavna skozi podobne situacije in prizore, ki seveda delujejo kot pomenljive metafore.

18 Tudi mladenič žalostno konča - uniformirani možje ga ubijejo na ulici; tik zatem - morda znova pomenljivo - sledi prizor v gledališču, ko se še Agnieszka simbolno zapiše svetu mrtvih.

19 Prim. Jensterle-Doležal, Mit o Antigoni, 234-36.

20 Morda lahko določeno simbolno razliko iščemo tudi v imenih, ki sta obe grškega izvora: ime Agnieszka je povezano s pridevnikom á $\gamma$ vó, čist, neomadeževan, svet; Irena pa s sa-

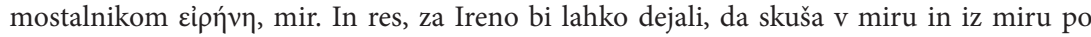
drugi svetovni vojni narediti največ; Agnieszka pa se ne želi umazati z nikakršnim kompromisom in se je za resnico pripravljena žrtvovati.

${ }_{21}$ Motiv Antigone v Katinu gre razumeti tudi kot navezavo na bogato poljsko tradicijo sodobnih obdelav antičnih mitov. Mit o Antigoni je bil na Poljskem (pa tudi pri drugih zahodnoin južnoslovanskih narodih) popularen predvsem konec petdesetih in začetek šestdesetih let prejšnjega stoletja, ko so ga avtorji navezovali na grozote druge svetovne vojne in povojne travme v zvezi z njo (glej Jensterle-Doležal, Mit o Antigoni, predvsem 69-73). 
A enako pomembne kot podobnosti $\mathrm{z}$ antično predlogo so tudi subtilne razlike, ki se izrišejo skozi filmsko pripoved. Če se Antigona sklicuje na bogove, se Agnieszka od cerkve odvrne; duhovniku, ki jo očitno dobro pozna in ji prvi pove za resnico o bratovi smrti, reče, da ga bo razočarala, saj ni prišla molit. Njen osebni razhod s cerkvijo se še poglobi kasneje, ko omenjenega duhovnika zaprejo, njegov namestnik pa iz strahu ne dovoli, da bi bratovo spominsko ploščo z dejansko letnico smrti postavila v cerkvi. Agnieszka je torej v svojem uporu povsem sama. Njena usoda pa se zdi še iz enega razloga bolj tragična od tiste, ki jo izkusi Sofoklova Antigona. Prizor, ki sklene njeno zgodbo v filmu, kaže prazno pokopališče in družinsko grobnico, kamor je na koncu dala postaviti bratovo spominsko ploščo. Ta je razbita; kos, ki manjka, je seveda mesto s krajem smrti in zadnjo, ključno številko letnice »1940«. Čeprav je seveda pomembno, da je pravilna letnica na nagrobniku bila, pa čeprav le za kratek čas, je dejstvo tudi, da Agnieszkin upor in kazen, ki mu sledi, ničesar konkretno ne spremenita; nihče se na koncu - kot pri Sofoklu ne spametuje, nihče ničesar ne spozna, nikomur ni žal. Človeku ob tem odmeva v spominu le pripomba zasliševalca, ki - na Agnieszkin odgovor, da je Nemci kot članico odporniškega gibanja niso uspeli zlomiti v petih letih samozavestno reče, da imajo oni veliko več časa kot Nemci. In res, resnica o Katinu je bila dokončno obelodanjena šele čez pol stoletja.

\section{V.}

Dominik Smole - če seveda pristajamo na takšno interpretacijo njegove Antigone - o povojnih pobojih domobrancev spregovori v drugem času. ${ }^{22}$ Antigona mu služi kot metafora $z a \mathrm{v}$ času nastanka igre še vedno tabuizirane (oziroma povsem zamolčane) dogodke, na katere $\mathrm{v}$ drami le namiguje; $\mathrm{v}$ tej zvezi bi lahko opozorili na samo situacijo (bratomorna vojna, en brat pokopan z vsemi častmi, drugi ne) in na nekatere replike, ki bi jih lahko razumeli kot skrivne namige na povojne pomore (npr. da morata sestri pred pokopom še najti Polinejka; da iščeta truplo po odročnih, mrzlih, opustelih krajih; ne nazadnje tudi dejstvo, da obstaja dvom, če Polinejkes sploh obstaja). Neposrednejših asociacij na sodobnost ne najdemo. Smoletu torej mit služi na bistveno drugačen način kot ustvarjalcem filma Katin. Služi mu za metaforo, skozi katero lahko sploh spregovori o zdajšnjosti.

Na to kaže že pristop k sami zgodbi, ki je pri slovenskem dramatiku bistveno drugačen kot pri poljskem cineastu. Če je poljska Antigona umeščena v točno določeno zgodovinsko obdobje in kraj, je Smoletova Antigona načeloma vsa ujeta v koordinate starega mita. Kraj dogajanja so mitološke Tebe, čas je po logiki stvari prav tako odmaknjen $\mathrm{v}$ starogrško mitologijo, vezan na

22 Prim. v prvi vrsti T. Hribar, Tragična etika svetosti, 269-350, in S. Hribar, »Pieteta in manipulacija«, passim (glej tudi Smole, Zbrano delo, 638-45, in 663-67). 
obdobje tik po legendarni bratomorni vojni med Eteoklom in Polinejkom, čeprav ga nekaj drobnih namigov na sodobnost (npr. omemba »raznašalca časopisa «, 785) na trenutke odmakne v nekakšno nedefinirano brezčasnost. V igri, ki se prav tako osredinja na Antigonin upor Kreontu in njegovi prepovedi Polinejkovega pokopa, nastopajo - razen Evridike - vse osebe, kot jih najdemo pri Sofoklu (dodana ji je le ena nova - paž). A vendar se Smole ne naslanja tudi na dramaturško zgradbo Sofoklove Antigone. V njegovi Antigoni bi zaman iskali prizore, ki bi bili - tako kot pri Wajdi - prevzeti ali navdahnjeni oziroma primerljivi z najslavnejšo antično tragedijo o Antigoni. Kljub temu je Sofokles seveda Smoletov referenčni okvir; Smole v veliki meri ohranja vsebinske poudarke, kot jih izrisujejo zgoraj omenjeni prizori iz Sofokla in Wajde.

Antigona se prav tako zaveže svetu mrtvih: ta je v drami definiran kot »druga plat življenja« (401). Zareza s tisto platjo življenja, polno brezskrbnega razkošja, kot jo junakinja pozna in ki je - kot poudarja na začetku igre - »lepa, lepa« (402), je povezana s temeljnim življenjskim spoznanjem. Ta rodi novo vodilo, nov odnos do življenja samega (415-19): ${ }^{23}$

Nisem le to, kar sem, in svet ni samo to,

kar vidim, čutim in otipljem.

Zakoni drugi vodijo življenje,

zato sem tu, da jih spoznam,

zato sem tu, da zvem, kdo sem.

$\mathrm{V}$ ta novi miselni krog ne sodi več zaročenec Hajmon. Takoj ko Antigona, kot poroča paž, začne misliti »nič lahke misli«(281), Hajmona za njo ni več (289-91):

Omenil sem ji Haimona: hotela je,

a ni in ni bilo ji moč ga obdržati v glavi.

Kar sfrčal je od nje.

Antigonina »druga plat življenja«, ki je zvezana s svetom mrtvih, je torej odpoved življenju, kamor sodi ljubezen, Hajmon, čigar - kot pravi zbor - »mlade roke iščejo objema« (357), bližajoča se poroka. Prav tako bi lahko govorili o nekakšni metaforični deželi, ki obstaja nekje vmes "med ljudmi in ... med sencami« (prim. Sofoklovo Antigono, 853) in v kateri se nahaja Antigona. Ta s svojim iskanjem Polinejka, kot že poudarjeno, stoji med dvema platema življenja; Antigona sama je - odkar si tako željno prizadeva za tisto, ki je pove-

${ }^{23}$ Vse navedke iz Smoletove Antigone, vključno s številkami verzov, navajam po citirani izdaji (Dominik Smole, Zbrano delo). Pri zapisovanju starogrških imen se držim ustaljenega načina in ne Smoletovih različic (tako pišem npr. »Tejrezias« in ne »Teiresias«); izjema so seveda imena $\mathrm{v}$ citatih. 
zana z mrtvim Polinejkom - z besedami zbora »/o/dsotna ... in kot da ni na svetu« (1699). Zaradi tega jo tisti, ki prisegajo na drugo, znano plat življenja, tudi uradno proglasijo za noro.

Prav tako Dominik Smole gradi na razliki med sestrama Antigono in Ismeno; do direktne konfrontacije med njima pred očmi gledalcev sicer ne pride, saj Antigona v igri ne nastopi, ${ }^{24}$ a o razlikah se podučimo skozi posredne opise in komentarje Ismene ter drugih oseb. Če je Ismena - »Ismena, / kjer sta mir in varnost « (31-32), je Antigona »zmeraj blodila pod oblaki / in delala vse táko, kar je dišalo zoper red «(1743-44). Če je prva v svojem uporu proti Kreontovemu ukazu neučakana, nastopaška, visokostna, polna visokoletečih, pompoznih besed, stalno poudarjajoč svojo čistost, nekrivdo, čast, je druga redkobesedna, razmišljujoča, $v$ začetku tudi polna dvomov in strahov. Če prva med iskanjem Polinejka postaja vedno bolj bolehna, šibka (njeno »telo je krhkejše od volje«, reče paž, 910), tudi vedno bolj nostalgična in željna nekdanjega življenja, ima druga - čim se za dejanje odloči - neomajno moč in voljo (s paževimi besedami, jo "veninven spodžiga žar velike vere«, 912). Ismena je, tudi če se upira, "po neki čudni igri zmeraj s kralji bot « (391); in res, že malce ostrejši pogovor s Kreontom zamaje njeno zgolj na videz trdno prepričanje v iskanje in pokop Polinejka. Antigona, nasprotno, s početjem nadaljuje in, kot pravi paž, »/v/sak dan je bližje in vse bližje cilju« (1577).

V slovenski Ismeni - za razliko od Sofokla in Wajde - ni nobene pozitivnosti; po razvojnem loku, ki ga - od začetne zavzetosti za dejanje do zloma naredi, deluje še kot toliko močnejši antipol Antigone. Ko se enkrat odpove sestri, se stopi z ostalimi osebami v nekakšnega kolektivnega junaka: z utrujenim Kreontom, razdvojenim med kralja, ki mu je vladanje spričo bolehnosti in glavobolov bolj kot ne odveč, in človeka, ki ga pomirja vrt s ptički in rožicami; s Tejrezijem, dvornim filozofom, razumnim, a predvsem že malo starim ter brez iluzij in vere, da je pomembno še kaj drugega razen "preprostih dejstev«: »slabo je biti lačen, / slabo je biti žejen, slabo brez toplega ognjišča» (86-87); z gizdalinskim uživačem Hajmonom. Tudi te osebe se seveda bistveno razlikujejo od svojih antičnih predhodnic, kot jih slika Sofokles.

Prav tako dobi posebne odtenke Antigonin upor. Antigona se sicer - kot Sofoklova - v osnovi upira ukazu novega vladarja Kreonta, ki zapoveduje, da Polinejk ne sme biti pokopan; a pomembno postane predvsem njeno iskanje Polinejka, ki preide »čez nebogljene mere« mrtvega brata (ta je bil sicer, kot njegov brat Eteokles, za časa življenja vse prej kot idealen). ${ }^{25}$ Iskanje Polinejkovega trupla se razširi »v nekaj, kar nosi svojo lastno težo« (1450-51): je iskanje tega, kdo človek zares je, njegovega lastnega prav. Prav zato se mora goditi na očeh vseh, » mimo laži vsakdanjosti, mimo varljive varnosti, / mimo slepote« (1186-87).

24 To zanimivo dramaturško domislico omenja tudi Steiner, Antigones, 170.

${ }^{25}$ Kot pravi o njiju Tejrezias (60-61): »Eden pijanec in nečistnik, / drugi stremuh brez mere." 
Polinejkes kot »misel«, za katero Antigona tako "vztrajno išče smisel« (118), ogroža obstoječi red, varni svet tebanskih dvorjanov, sestavljen zgolj iz tistega, »kar vidiš, čutiš in otiplješ s prsti« (322) in v katerem je glavno, da so »vsesplošni posli tako/ lepo, vsesplošno, umno in prikladno ... urejeni« (54-56). Antigonino iskanje ogroža dvorjane kljub uradni razglasitvi, da je slaboumna: saj, kot opaža Hajmon, »/o/dkar je ona blazna, je vsaka reč glasnejša« (1756). Najglasnejše je seveda dejstvo, da dokler Antigona išče Polinejka, slednji in vse, kar ta predstavlja, - nepreklicno je. Tebanski dvorjani si seveda želijo potrditve, da ga ni, saj - kot strne Ismena: „Če Polineikes je, čemu smo mi? « (1928) Ali, z besedami vidca Tejrezia, ki zahteva od Kreonta (1875-78):

Povej jasno in glasno vsem:

do te višine seže človek,

ne večji ni, ne manjši kakor smo vsi drugi,

nič višjega ni na tem božjem svetu!

Antigona je v vsem, kar je prevzeto iz antike, sama proti vsem: še glasnik iz Delfov sporoči tisto, kar želijo njeni antagonisti, namreč, da Polinejka ni. V tem je primerljiva z Wajdovo Agnieszko. A slovenska Antigona vendarle ima zaveznika - paža, osebo, ki jo Smole uvede na novo. Ta je na njeni strani in na koncu ostane tisti, ki - tudi ko je Antigona ubita - bo, kot je slutiti, še naprej ogrožal varljivo varni svet Smoletovih tebanskih dvorjanov.

Ta ideja je tudi edino, kar se v Smoletovi Antigoni izrazi na izrazito čustveni, nerazumski ravni, primerljivi z učinki antičnih ritualov, transponiranih na gledališki oder. Če je sicer Antigona v prvi vrsti igra dialoga, besedilo ob koncu narekuje dogajanje, ki učinkuje onkraj besed - zvenenje zvonov. Njihov pomen je interpretiran trikrat. Najprej ga Ismena razume kot potrdilo vsesplošnega olajšanja ob sporočilu iz Delfov, da Polinejka ni. Nato paž, ki brez sape priteče na prizorišče, $\mathrm{v}$ grozo Tebancev pove, da zvonovi oznanjajo vsem (2226): »Antigona je našla Polineika!« In končno - potem ko Kreon Antigono zapiše smrti in si tebanski dvorjani vnovič oddahnejo - v daljavi ponovno zazvenijo zvonovi, »čedalje glasnejši in ušesom kar neprijetni«, kot pravi sklepna didaskalija. Ti pomenljivo spremljajo in poudarjajo sklepno ter za Antigonine antagoniste toliko bolj strašljivo spoznanje, da je paž, Antigonin goreči privrženec, še vedno živ.

VI.

Prav oseba paža in ritualno zvonjenje, povezano z njegovim sporočilom o Antigonini najdbi Polinejka in $\mathrm{z}$ dejstvom, da sam ostaja živ, nas popelje nazaj h katinski Antigoni. 
Tako Wajdova Agnieszka kot Smoletova Antigona namreč v končni fazi sprožita vprašanje, kaj njun upor in z njim njuna smrt pravzaprav pomenita. V Katinu se smiselnost Agnieszkinega dejanja postavi pod vprašanj predvsem zato, ker je resnica, za katero si prizadeva, razkrita le za kratek hip. ${ }^{26}$ Pri Smoletu Antigonino dejanje iz istega razloga postavi pod vprašaj Ismena, ko - ob sestrini smrtni obsodbi - olajšana izreče besede, ki bi se povsem lahko, seveda mutatis mutandis, nanašale na Agnieszko (2256-59):

Antigona je našla Polineika, ampak samo za kratek hip, le za trenutek.

Kaj naj z Antigono samo za trenutek?

Rahel cvet, ki se odpre in brž nato usuje.

Smiselnost boja obeh Antigon je torej na neki točki zaradi kratkotrajnosti uspeha v obeh delih postavljena pod vprašaj. Pri Smoletu dvom eksplicitno ubesedi Ismena, pri filmu ga je porodil (na vsak način subjektiven) občutek podpisane gledalke. A vendar se človek ob gledanju Katina tudi intuitivno vseskozi zaveda, da je dejanje samo, pa čeprav so njegove posledice vidne »samo za trenutek«, še kako pomembno. Pri Smoletu se zdi prav ta občutek poudarjen z zvokom zvonov, ki v naših ušesih sugerirajo ritual - personificiran v osebi paža. Ta »mili pšeničnolasi deček« (1623) potrjuje, da ima težnja za resnico ter prizadevanje za drugo, višjo "plat življenja« - smisel.

\section{BIBLIOGRAFIJA}

Bendann, Effie. Death Customs: An Analytical Study of Burial Rites. London: K. Paul, Trench, Trübner, New York: Knopf, 1930.

Bowie, Angus M. Aristophanes: Myth, ritual and comedy. Cambridge: Cambridge University Press, 1993.

Brown, Andrew, izd. Sophocles, Antigone. Warminster: Aris \& Phillips Ltd, 1987. Easterling, Patricia E. »Tragedy and Ritual.« V: Theater and Society in the Classical World, ur. Ruth Scodel, 7-23. Ann Arbor: University of Michigan Press, 1993.

Foley, Helene P. Ritual Irony: Poetry and Sacrifice in Euripides. Ithaca: Cornell University Press, 1985.

Gantar, Kajetan, prev. Sofokles: Antigona, Kralj Ojdipus. Ljubljana: Mladinska knjiga, 1992.

Golder, Herbert. »Preface.« Arion 3, št. 1 (1994): 1-5.

Goldhill, Simon. »Programme notes. V: Performance Culture and Athenian Democracy, ur. Simon Goldhill in Robin Osborne, 1-29. Cambridge: Cambridge University Press, 1999.

26 Morda k temu pripomore tudi lik Irene, ki ima - kot že omenjeno - pozitivne lastnosti, celo dimenzije skrivnega upora proti oblasti. Irena ni toliko bojazljiva, kot se zdi realna; njeno razmišljanje in delovanje se morda na neki pragmatični ravni zdi bolj učinkovito kot upor Agnieszke, ki, nasprotno, absolutno zavrača vsakršen kompromis. 
Graf, Fritz. »Religion and drama.« V: The Cambridge Companion to Greek and Roman Theatre, ur. Marianne McDonald in J. Michael Walton, 55-71. Cambridge: Cambridge University Press, 2007.

Haldane, Joan A. »A scene in the Thesmophoriazusae (295-371). Philologus 109 (1965): 39-46.

Hribar, Spomenka. »Pieteta in manipulacija.« V: Dominik Smole, ur. Ivo Svetina, 121-62. Interpretacije 5. Ljubljana: Nova revija, 1996.

Hribar, Tine. Tragična etika svetosti. Ljubljana: Slovenska matica, 1991.

Isak Kres, Jelena, prev. Evripid: Helena. Ljubljana: Modrijan, 2006.

Jensterle-Doležal, Alenka. Mit o Antigoni v zahodno- in južnoslovanskih dramatikah sredi 20. stoletja. Ljubljana: Slovenska matica, 2004.

Kavoulaki, Athena. ПОМПАI: Processions in Athenian Tragedy. Doktorska disertacija. Oxford: University of Oxford, 1996.

Kavoulaki, Athena. "Processional performance and the democratic polis."V: Performance Culture and Athenian Democracy, ur. Simon Goldhill in Robin Osborne, 293-320. Cambridge: Cambridge University Press, 1999.

Martin, Richard P. »Ancient theatre and performance culture.« V: The Cambridge Companion to Greek and Roman Theatre, ur. Marianne McDonald in J. Michael Walton, 36-54. Cambridge: Cambridge University Press, 2007.

Michelakis, Pantelis. „Greek Tragedy in Cinema." V: Dionysus since 69: Greek tragedy at the dawn of the third millennium, ur. Edith Hall, Fiona Macintosh in Amanda Wrigley, 199-218. Oxford: Oxford University Press, 2005.

Rehm, Rush. Greek Tragic Theatre. London in New York: Routledge, 1992.

Smole, Dominik. Zbrano delo. Dramski spisi I. Antigona. Uredil Goran Schmidt. Zbrana dela slovenskih pesnikov in pisateljev 224. Maribor: Litera, 2006 (ponatis 2009).

Steiner, George. Antigones: The Antigone myth in Western literature, art and thought. 2. izd. Oxford: Clarendon Press, 1986.

Tambiah, Stanley Jeyaraja. Culture, Thought, and Social Action: An Antropological Perspective. Cambridge, Mass.: Harvard University Press, 1985.

Tzanetou, Angeliki. »Almost Dying, Dying Twice: Ritual and Audience in Euripides' Iphigenia in Tauris." V: Euripides and Tragic Theatre in the Late Fifth Century, ur. Martin J. Cropp et al., 199-216. Illinois Classical Studies 24/25. Champaign: Stipes Publishing, 2000.

\section{AGNIESZKA, ANTIGONE: THE ANTIGONE MYTH IN ANDRZEJ WAJDA'S KATYN AND IN DOMINIK SMOLE'S ANTIGONA}

\section{Summary}

The article considers two modern works which employ the Antigone myth. The Polish film director Andrzej Wajda included several implicit allusions to the myth in his Katyn (2007), a film about the mass murder of Polish officers and intelligentsia - a Soviet crime which remained a taboo for almost half a century. On the other hand, Dominik Smole, a Slovenian playwright, wrote a play about Antigone (1960), which is set from beginning to end in ancient Thebes. It has been suggested that his play indirectly calls attention to the Slovenian post-war killings of the Slovenian Home Guard members, which were likewise long tabooed. 
Inquiring how the two works relate to Sophocles' Antigone, the article points out that Andrzej Wajda seems inspired not only by Sophocles' ideas but also by his dramatic techniques. A scene that seems especially interesting in this respect presents Agnieszka (Antigone) going to the theatre to sell her hair in order to buy a tombstone for her dead brother Piotr (Polyneikes). The action in the theatre is so full of metaphors and subtle imagery that it can be compared to one of the most compelling scenes in Sophocles' Antigone (801-943). In the latter, Sophocles employs a popular ancient dramatic technique, incorporating ritual elements in the dramatic action in order to create an atmosphere rich in meanings and connotations. While Wajda's film includes at least two other scenes which seem directly inspired by the dramaturgical composition of Sophocles' tragedy, Dominik Smole does not appear to make much use of Sophoclean techniques. To both authors, however, Sophocles is a key reference for their characters, situations, and dilemmas; both the film and the play refer to the ancient tragedy either through similarities or differences established in relation to the ancient Antigone. With regard to the differences, Smole's only new persona dramatis, the page who survives Antigone as her devoted follower, appears to be one of the most arresting ones. It is remarkable that Smole accompanies the page's final act at the end of the play with a singular ritualistic atmosphere.

Concerning the function of the myth in the works discussed, it may be concluded that Andrzej Wajda, having shot his film at a time when events in the Katyn forest were no longer a taboo, drew on the myth in order to give his historical film a universally tragic dimension. For Dominik Smole, who composed his Antigone almost fifty years earlier, in a period when the traumatic killings could not be openly addressed, the mythological metaphor was probably the only way to discuss problematic contemporary issues. 